\title{
Erratum to: Novel Electrically Stimulated Catalytic Converter Prototype for Replacement of Conventional Auto Exhaust Emission Converters
}

\author{
HAMADE Thomas A. \\ (University of Michigan - Shanghai Jiao Tong University Joint Institute, \\ Shanghai Jiao Tong University, Shanghai 200240, China)
}

(C) Shanghai Jiao Tong University and Springer-Verlag GmbH Germany, part of Springer Nature 2020

The original version of this article unfortunately contained outdated email address in footing, page 85. The updated email address is given below.

E-mail: hamadeta@udmercy.edu

The online version of the original article can be found at https://doi.org/10.1007/s12204-018-1913-1.

E-mail: hamadeta@udmercy.edu 